\title{
A relapsed Pseudomonas stutzeri prosthetic valve endocarditis: a case report and review of the literature
}

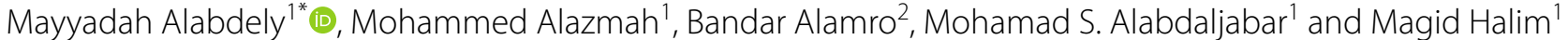

\begin{abstract}
Background: Pseudomonas stutzeri is a nonfluorescent denitrifying bacterium widely distributed in the environment, and it has also been isolated as an opportunistic pathogen from humans. It is a Gram-negative bacterium and a common inhabitant of soil and water.

Case presentation: We report the case of a 51-year-old arab gentleman who has systemic lupus erythematous complicated by lupus nephritis and underwent renal transplantation twice. He underwent mitral valve replacement and 4 years later was diagnosed with prosthetic valve endocarditis caused by Pseudomonas stutzeri.

Conclusions: Literature review was conducted and revealed that this pathogen may be of a particular medical relevance in immunocompromised patients. Our case proves that early infection and relapse despite optimal antibiotics course are possible outcomes of Pseudomonas stutzeri endocarditis. To the best of our knowledge, this is the second case of fulminant early prosthetic valve endocarditis occurring only 1 month post-cardiac surgery with relapse despite a complete antibiotics course.
\end{abstract}

Keywords: Pseudomonas stutzeri, Infective endocarditis, Prosthetic valve, Diagnosis, Infection, Case report, Saudi Arabia

\section{Introduction}

Infective endocarditis (IE) is a rare yet serious condition that is associated with poor prognosis if not appropriately managed. The most common causative organisms are Gram-positive bacteria; however, Gram-negative counterparts can also lead to IE, and are associated with poor prognosis [1]. In the Gram-negative group, Pseudomonas aeruginosa is considered a common causative agent, but other pseudomonal species are extremely rarely found as a culprit in IE.

Pseudomonas stutzeri is a Gram-negative bacillus that belongs to the Pseudomonas genus. It plays a vital role

\footnotetext{
*Correspondence: Mayyadah.h.alabdely@gmail.com

${ }^{1}$ Department of Medicine, King Faisal Specialist Hospital and Research Center, Riyadh, Saudi Arabia
}

Full list of author information is available at the end of the article in various ecosystems, with different beneficial applications [1]. Nonetheless, $P$. stutzeri can be harmful, as it is capable of infecting the human body. It is considered an opportunistic organism and can affect different systems in the human body [2], albeit rarely. To the best of our knowledge, $P$. stutzeri was previously shown to underlie IE in only six cases in the literature from all around the globe. Herein, we present a unique case of recurrent IE caused by $P$. stutzeri 6 weeks after complete remission in a 51-year-old man with a bioprosthetic mitral valve.

\section{Case report}

A 51-year-old arab man, known to have systemic lupus erythematosus (SLE) complicated with lupus nephritis. He underwent renal transplantation twice in 1997 and 2019 and was maintained on prednisone $5 \mathrm{mg}$ once daily and tacrolimus $1 \mathrm{mg}$ twice per day. He also is known to original author(s) and the source, provide a link to the Creative Commons licence, and indicate if changes were made. The images or other third party material in this article are included in the article's Creative Commons licence, unless indicated otherwise in a credit line to the material. If material is not included in the article's Creative Commons licence and your intended use is not permitted by statutory regulation or exceeds the permitted use, you will need to obtain permission directly from the copyright holder. To view a copy of this licence, visit http://creativecommons.org/licenses/by/4.0/. The Creative Commons Public Domain Dedication waiver (http://creativeco mmons.org/publicdomain/zero/1.0/) applies to the data made available in this article, unless otherwise stated in a credit line to the data. 
have severe mitral valve stenosis secondary to rheumatic heart disease. His family history was unremarkable; particularly, there was no history of SLE or rheumatic heart diseases. He works as a businessman, is married, and has two children. He lives in a private house and does not consume alcohol or tobacco.

At the age of 45 years, a successful mechanical mitral valve replacement (MVR) procedure was performed utilizing Medtronic valve size $29 \mathrm{~mm}$. He was maintained on warfarin $4 \mathrm{mg}$ daily with a subtherapeutic internal normalization ratio (INR) due to noncompliance issues. Four years later, he was found to have a stuck mechanical mitral valve leaflet by a routine transthoracic echocardiography, which was confirmed by transesophageal echocardiography (TEE) and fluoroscopy. He was asymptomatic clinically, and his physical examination was remarkable for an audible click of the first heart sound (S1), normal second heart sound (S2), and a grade $2 / 6$ pan-systolic murmur over his apical area. As a result, a redo MVR was performed utilizing a bioprosthetic valve (Epic St. Jude bioprosthesis size $31 \mathrm{~mm}$ ).

One month later, he presented to emergency room complaining of subjective fever, reaching up to $39{ }^{\circ} \mathrm{C}$, associated with chills for a 2-day duration. His heart rate was 86 beats per minute and blood pressure was $118 / 67 \mathrm{mmHg}$. His physical examination revealed a normal pulse and no splinter hemorrhages, Osler nodes, or Janeway lesions. His precordial examination revealed normal and audible S1 and S2 with grade 3/6 pansystolic murmur over his apical area that radiated to his axilla. His higher mental function and neurological examination were normal, and his ophthalmological examination excluded the presence of Roth's spots. His dental examination revealed few dental caries, and he denied any recent dental or gingival procedures or manipulations. Blood cultures were obtained for investigations, and the patient was discharged on oral paracetamol $650 \mathrm{mg}$ orally every 4 hours as needed. His blood cultures came back with a positive result of isolated $P$. stutzeri.

The patient was called back and admitted for urgent investigations, where he underwent a transthoracic echocardiography that revealed vegetations on the bioprosthetic mitral valve. Subsequently, a TEE was performed and revealed two medium-sized vegetations attached to both atrial and ventricular sides of the mitral prosthesis. They measured approximately $5 \times 4 \mathrm{~mm}$ and $7 \times 6 \mathrm{~mm}$, respectively, morphologically consistent with prosthetic valve endocarditis (PVE), rather than Libman-Sacks Endocarditis. Rheumatological investigations were negative, and he had stable and inactive SLE. The patient was treated as a case of PVE with intravenous piperacillin/ tazobactam 4.5 g every 6 hours for 3 weeks as an inpatient and was discharged thereafter in stable condition on oral ciprofloxacin $400 \mathrm{mg}$ twice a day to complete a total duration of 6 weeks, based on his blood culture sensitivity results (Table 1 ).

Two months later, he again presented to emergency room complaining of fever, reaching $38.3^{\circ} \mathrm{C}$, and chills. His symptoms were associated with dysarthria and aphasia. His physical examination was notable for a heart rate of 87 beats per minute and blood pressure of $136 / 78 \mathrm{mmHg}$. A reduced power of grade 2 over 5 was noted in his right upper and right lower limbs. His cardiovascular examination was remarkable for a normal and audible S1 and S2 with a grade 4 over 6 pansystolic murmur over his apical area. There were no peripheral stigmata of infective endocarditis. While in emergency room, he lost consciousness and was intubated and placed on mechanical ventilation. Computed tomography (CT) scan of his brain revealed a completely occluded left middle cerebral artery (MCA); unfortunately, thrombolysis was not feasible because of a high INR level (4.9). Subsequent brain magnetic resonance imaging (MRI) revealed multiple brain and brainstem lesions, which were suggestive of underlying showering emboli.

His routine blood work-up was unremarkable, apart from leukocytosis of a $16.3 \times 10^{9}$ per liter and a positive blood culture growing the same organism, $P$. stutzeri. His hemoglobin level, platelet count, and renal and hepatic profiles were all within normal range. His serological markers were negative. Intravenous ceftazidime $2 \mathrm{~g}$ every 12 hours was started, and the patient underwent TEE, which revealed several mobile masses attached to the atrial side and coating the bioprosthetic mitral valve consistent with vegetations (Fig. 1). The vegetations were extending to involve the aortomitral fibrosa and the aortic valve causing severe degree of aortic regurgitation and suggesting an ongoing abscess formation.

The case was discussed in a combined cardiology/ cardiac surgery meeting, and the decision was made for the patient to undergo a second redo MVR. After redo sternotomy, dissection of adhesions, and cardiopulmonary bypass connection, the prosthetic valve

Table 1 Susceptibility profile of the P. stutzeri isolate

\begin{tabular}{ll}
\hline Tested antibiotics & $\begin{array}{l}\text { Reported } \\
\text { susceptibility }\end{array}$ \\
\hline Ceftazidime & Sensitive \\
Cefepime & Sensitive \\
Gentamicin & Sensitive \\
Tobramycin & Sensitive \\
Imipenem & Sensitive \\
Meropenem & Sensitive \\
Ciprofloxacin & Sensitive \\
\hline
\end{tabular}




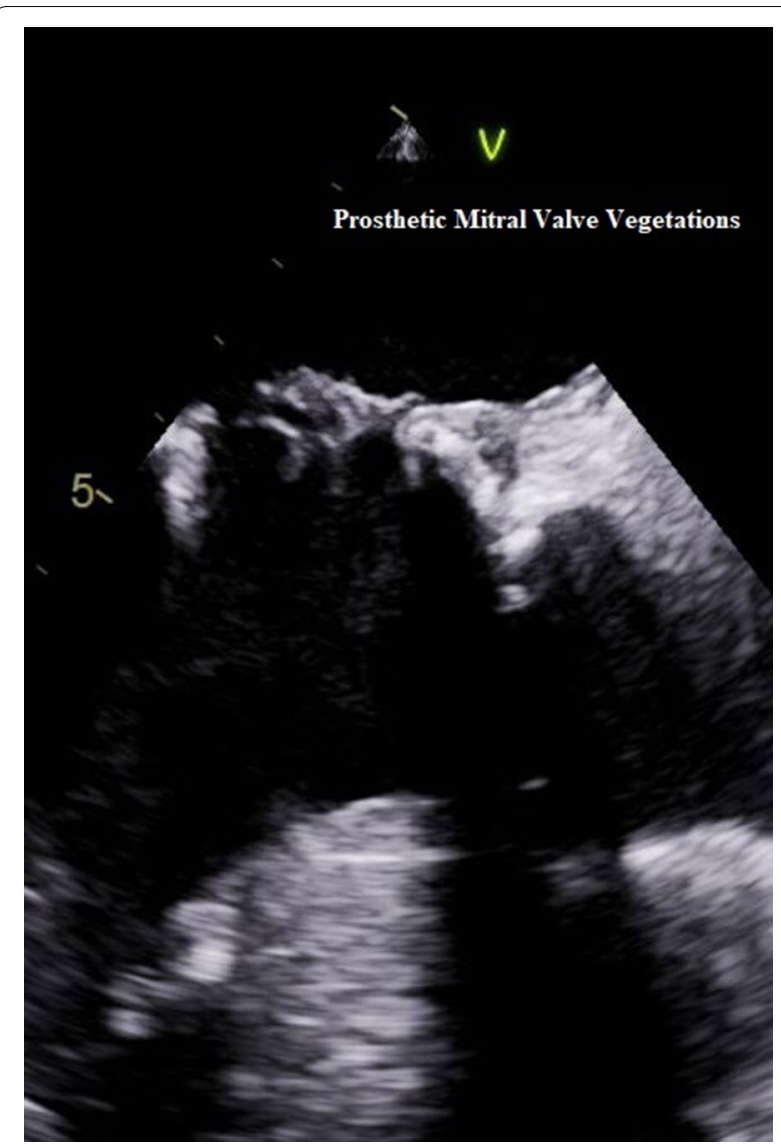

Fig. 1 Transesophageal echocardiography showing the prosthetic mitral valve with vegetations attached to the atrial surface

was explored. The prosthetic mitral valve leaflets were thickened and coated with multiple gross masses consistent with vegetations (Fig. 2); similar masses were also noted on the aortic valve cusps. The prosthetic mitral valve was excised and replaced with a $33 \mathrm{~mm}$ bioprosthesis (Perimount Magna Ease); the aortic valve was also excised and replaced with a size $25 \mathrm{~mm}$ bioprosthesis (Perimount Magna Ease). The excised valves and masses were sent for histopathological examination, which confirmed the presence of vegetations, and the surgical cultures grew the same organism. The postoperative period was unremarkable, and the antimicrobials regimen were continued throughout his hospital stay.

The patient was seen at a follow-up visit 6 months after his surgery, where his sternal wound was intact and revealed no signs of active infection or inflammation. He had an intact higher mental function with no aphasia or dysarthria, and his right upper and lower limbs power was 4 over 5 . His physical examination was otherwise unremarkable.

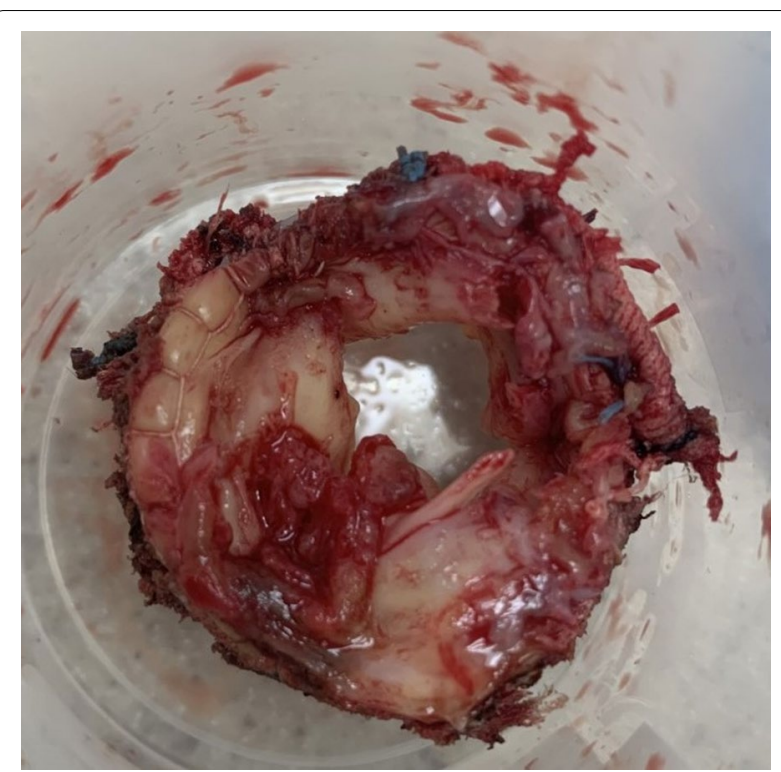

Fig. 2 The excised mitral valve prosthesis showing leaflets thickening with multiple gross masses consistent with vegetations

\section{Discussion}

This is a case of a 51-year-old gentleman, who has SLE complicated by lupus nephritis and who underwent renal transplantation twice. He underwent mitral valve replacement and 4 years later was diagnosed with prosthetic valve endocarditis caused by $P$. stutzeri complicated with a left MCA stroke. He underwent a redo MVR successfully and made a reasonable recovery on 6-month follow-up.

Prosthetic valve infective endocarditis following surgical valve replacement occurs in $1-3 \%$ of patients in the first year after surgery and is associated with high morbidity and mortality [3]. Gram-negative pathogens account for less than $10 \%$ of all cases of infective endocarditis worldwide [4,5]. While Pseudomonas species rarely cause prosthetic valve endocarditis, Pseudomonas aeruginosa is the most frequently implicated pathogen in this group [4]. P. stutzeri with its low virulence and high susceptibility to antibiotics has not been frequently implicated in prosthetic valve endocarditis [6].

Pseudomonas stutzeri was first described by Burri and Stutzer in 1895 [7]. This Gram-negative, rod-shaped, aerobic, and oxidative-positive bacterium is naturally found in soil and water [2]. True human infections with this bacterium occur particularly in immunocompromised patients with chronic comorbidities, a history of previous surgery, previous trauma, or skin infections, and are frequently related to prosthetic devices. To date, many cases of $P$. stutzeri infection have been reported in the literature, including bacteremia, pneumonia, osteomyelitis, 
arthritis, and ocular infections $[6,8]$. It has also been hypothesized that $P$. stutzeri infections may develop more easily in inflamed tissue, as was observed in two patients being treated for pulmonary tuberculosis with considerable parenchymal destruction who developed complicating superinfections with $P$. stutzeri $[9,10]$.

Pseudomonas stutzeri is rarely reported as a pathogenic agent of infective endocarditis, with only six cases having been reported previously in the literature (Table 2). Cases were reported from Israel, Spain, France, Lebanon, and Saudi Arabia. Four cases of $P$. stutzeri prosthetic valve infective endocarditis occurred, on average, 4 years postcardiac surgery, while two cases affected a native valve in patients with no prior surgical history. The source of infection could not be identified in any of the cases. All patients were successfully treated with surgery and antibiotics and survived, except one patient $[8,11-14]$.

A striking geographical distribution of $P$. stutzeri infections has been observed, with $62 \%$ of all globally reported cases being detected in the Mediterranean Basin, most frequently in Israel $(n=30)$, Spain $(n=5)$, Italy $(n=3)$, and Turkey $(n=3)$. It remains unclear whether these observations relate to higher rates of contaminated medical equipment and devices in this region or whether there are specific biological factors favoring the growth of $P$. stutzeri in such environments. Further investigations are warranted to elucidate these associations [8].

There are no data comparing monotherapy with combination therapy for Pseudomonas aeruginosa endocarditis, mainly due to the rarity of the condition. Recommendation to use combination therapy with two antipseudomonal antibiotics including an aminoglycoside is based mainly on expert opinion and observational studies. There are no data regarding the optimal treatment of P. stutzeri endocarditis [13].
In our case, the source of infection and the portal of entry could not be identified. The patient underwent a redo mitral valve replacement, and a month later he presented with symptoms suggestive of a prosthetic valve endocarditis. The diagnosis was confirmed by a positive blood culture that grew P. stutzeri and a transesophageal echocardiography. The isolated organism was susceptible to a wide range of antibiotics as in previously reported cases, so the decision was made to treat him with a 6-week course of antibiotics. Unfortunately, and despite completing the full antibiotics course, he relapsed 2 months later, requiring a more aggressive management with combined antibiotics and a second redo mitral valve replacement. Unlike the majority of the previous reported cases of $P$. stutzeri infective endocarditis, this is a reported case from a country that does not belong to Mediterranean Basin. An indolent clinical course was also well documented in the Grimaldi et al. case with relapse after 4 years [12]. To the best of our knowledge, this is the second case of fulminant early prosthetic valve endocarditis occurring only 1 month post-cardiac surgery with relapse despite a complete antibiotics course.

\section{Conclusion}

Pseudomonas stutzeri, even though frequently considered as contaminant, can give rise to potentially severe infections, including endocarditis. Those infections are being identified and recognized more frequently. The source of infection remains unclear. P. stutzeri isolates remain susceptible to a wide array of antibiotics. Endocarditis typically occurs years after cardiac surgery with a good overall outcome. Our case proves that early infection and relapse despite the optimum antibiotics course are possible outcomes of $P$. stutzeri endocarditis.

Table 2 Previous cases of P. stutzeri infective endocarditis

\begin{tabular}{|c|c|c|c|c|c|c|c|}
\hline Cases & $\begin{array}{l}\text { Year of } \\
\text { publication }\end{array}$ & Country & Valve & Antibiotics & Surgery & Outcome & $\begin{array}{l}\text { Time after } \\
\text { cardiac } \\
\text { surgery }\end{array}$ \\
\hline Rosenberg et al. [15] & 1987 & Israel & Prosthetic mitral & $\begin{array}{l}\text { Tobramycin and } \\
\text { mezlocillin }\end{array}$ & Not done & Cured & 2 years \\
\hline López et al. [11] & 2002 & Spain & Native aortic & $\begin{array}{l}\text { Aztreonam, cefotax- } \\
\text { ime, and ceftriaxone }\end{array}$ & $\begin{array}{l}\text { Aortic valve replace- } \\
\text { ment }\end{array}$ & Cured & Not applicable \\
\hline Grimaldi et al. [12] & 2008 & France & Prosthetic aortic & $\begin{array}{l}\text { Cefotaxime, ciproflox- } \\
\text { acin, and doxycycline }\end{array}$ & Not done & Cured & 6 and 10 years \\
\hline Shalabi et al. [8] & 2017 & Lebanon & $\begin{array}{l}\text { Prosthetic aortic and } \\
\text { mitral }\end{array}$ & Ceftazidime & $\begin{array}{l}\text { Aortic valve replace- } \\
\text { ment }\end{array}$ & Cured & 3 years \\
\hline Halabi et al. [13] & 2018 & Lebanon & Prosthetic aortic & Ceftazidime & $\begin{array}{l}\text { Aortic and tricuspid } \\
\text { valves replacement }\end{array}$ & Deceased & 26 days \\
\hline Alwazzeh et al. [14] & 2020 & Saudi Arabia & $\begin{array}{l}\text { Native mitral and } \\
\text { aortic }\end{array}$ & $\begin{array}{l}\text { Vancomycin, ceftriax- } \\
\text { one, and cefepime }\end{array}$ & $\begin{array}{l}\text { Mitral and aortic } \\
\text { valves replacement }\end{array}$ & Cured & Not applicable \\
\hline
\end{tabular}




\section{Acknowledgements \\ Not applicable.}

\section{Authors' contributions}

Study conception and design, MAlabdely and MAlazmah; collection of clinical data, MAlabdely and MAlabdaljabar; reference search, MAlabdely and MAlazmah; obtaining figures and photos, BA; original draft preparation, MAlabdely; review of original draft, MAlabdely, BA, and $\mathrm{MH}$; editing and finalization of report, MAlabdely and MH. All authors read and approved the final manuscript.

\section{Funding}

This research did not receive any specific grant from funding agencies in the public, commercial or no-to-profit sectors.

\section{Availability of data and materials}

Not applicable.

\section{Declarations}

Ethics approval and consent to participate

Not applicable.

\section{Consent for publication}

Written informed consent was obtained from the patient for publication of this case report and any accompanying images. A copy of the written consent is available for review by the Editor-in-Chief of this journal.

\section{Competing interests}

The authors have no conflicts of interest to declare.

\section{Author details}

${ }^{1}$ Department of Medicine, King Faisal Specialist Hospital and Research Center, Riyadh, Saudi Arabia. ${ }^{2}$ Heart Center, King Faisal Specialist Hospital and Research Center, Riyadh, Saudi Arabia.

Received: 22 June 2021 Accepted: 31 August 2021

Published online: 10 October 2021

\section{References}

1. Raza SS, Sultan OW, Sohail MR. Gram-negative bacterial endocarditis in adults: state-of-the-heart. Expert Rev Anti Infect Ther. 2010;8(8):879-85.

2. Lalucat J, Bennasar A, Bosch R, García-Valdés E, Palleroni NJ. Biology of Pseudomonas stutzeri. Microbiol Mol Biol Rev. 2006;70(2):510-47.
3. Mihos CG, Capoulade R, Yucel E, Picard MH, Santana O. Surgical versus medical therapy for prosthetic valve endocarditis: a meta-analysis of 32 studies. Ann Thorac Surg. 2017:103:991-1004.

4. Ambrosini J, Hernandez-Meneses M, Tellez A, Pericas J, Falces C, et al. The changing epidemiology of infective endocarditis in the twenty-first century. Curr Infect Dis Rep. 2017;19:21.

5. Vogkou CT, Vlachogiannis NI, Palaiodimos L, Kousoulis AA. The causative agents in infective endocarditis: a systemic review comprising 33,214 cases. Eur J Clin Microbiol Infect Dis. 2016:35:1227-45.

6. Noble RC, Overman SB. Pseudomonas stutzeri infection. A review of hospital isolates and a review of the literature. Diagn Microbiol Infect Dis. 1994;91:51-6.

7. Burri R, Stutzer A. Über Nitrat zerstörende Bakterien und den durch dieselben bedingten Stickstoffverlust. Zentbl Bakteriol Parasitenkd. 1895;1:257-65 (In German).

8. Shalabi A, Ehrlich T, Schafers HJ, Becker SL. Infective endocarditis caused by Pseudomonas stutzeri in a patient with Marfan syndrome: case report and brief literature review. IDCases. 2017;10:22-5.

9. Loyse A, Storring RA, Melzer M. Pseudomonas stutzeri pneumonia in an HIV sero-positive patient. J Infect. 2006:53:75-6.

10. Lin KH, Chen CM, Wang JH, Ho MW. Pseudomonas stutzeri necrotizing pneumonia in pre-existing pulmonary tuberculosis. Intern Med. 2014;53:2543-6.

11. López A, Baraia-Etxaburu J, Ezpeleta C, Teira R, Ayarza R, Cisterna R, Santamaría JM. Multimicrobial endocarditis caused by Streptococcus salivarius and Pseudomonas stutzeri: good course after early surgery. An Med Interna. 2002. https://doi.org/10.4321/S0212-71992002000100017.

12. Grimaldi D, Podglajen I, Aubert A, Buu-Hoï A, Diebold B, Mainardi J-L. Case of indolent endocarditis due to Pseudomonas stutzeri with genetic evidence of relapse after 4 years. J Clin Microbiol. 2009;47:503-4.

13. Halabi Z, Mocadie M, El Zein S, Kanj S. Pseudomonas stutzeri prosthetic valve endocarditis: a case report and review of the literature. J Infect Public Health. 2019:12:434-7.

14. Alwazzeh MJ, Alkuwaiti FA, Alqasim M, Alwarthan S, El-Ghoneimy Y. Infective endocarditis caused by Pseudomonas stutzeri: a case report and literature review. Infect Dis Rep. 2020;12(3):105-9. https://doi.org/10. 3390/idr12030020.

15. Rosenberg I, Leibovici L, Mor F, Block C, Wysenbeek AJ. Pseudomonas stutzeri causing late prosthetic valve endocarditis. J R Soc Med. 1987:80:457-9.

\section{Publisher's Note}

Springer Nature remains neutral with regard to jurisdictional claims in published maps and institutional affiliations.

Ready to submit your research? Choose BMC and benefit from

- fast, convenient online submission

- thorough peer review by experienced researchers in your field

- rapid publication on acceptance

- support for research data, including large and complex data types

- gold Open Access which fosters wider collaboration and increased citations

- maximum visibility for your research: over $100 \mathrm{M}$ website views per year

At $\mathrm{BMC}$, research is always in progress.

Learn more biomedcentral.com/submissions 